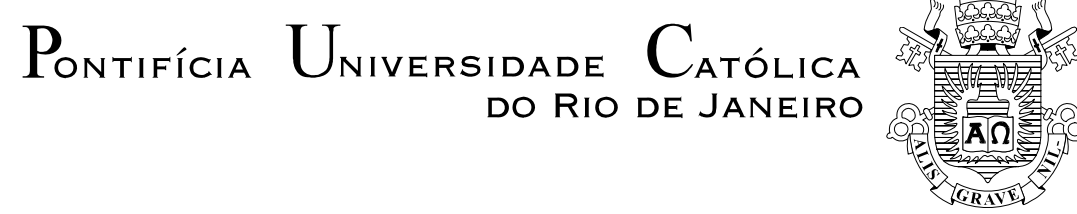

Elisângela Aparecida Alves

\title{
CONVERGÊNCIA DIGITAL E O FUTURO DO LIVRO
}

\section{Dissertação de Mestrado}

Dissertação apresentada ao Programa de Pós-Graduação em Letras da PUC-Rio como requisito parcial para obtenção do título de Mestre em Letras.

Orientadora: Profa. Eliana L. M. Yunes Garcia 


$$
\begin{array}{r}
\text { Pontifícia Universidade Católica do Rio de Janeiro } \\
\text { dom }
\end{array}
$$

Elisângela Aparecida Alves

\section{CONVERGÊNCIA DIGITAL E O FUTURO DO LIVRO}

Dissertação apresentada como requisito parcial para obtenção do grau de Mestre pelo programa de PósGraduação em Letras do Departamento de Letras do Centro de Teologia e Ciências Humanas da PUC-Rio. Aprovada pela Comissão Examinadora abaixo assinada.

Profa. Eliana Lúcia Madureira Yunes Garcia

Orientadora

Departamento de Letras - PUC-Rio

Prof. Aníbal Francisco Alves Bragança

UFF

Prof. Érico Braga Barbosa Lima Cátedra Unesco de Leitura - PUC-Rio

Prof. Paulo Fernando Carneiro de Andrade Coordenador Setorial do Centro de Teologia

e Ciências Humanas - PUC-Rio

Rio de Janeiro, 30 de abril de 2010. 
Todos os direitos reservados. É proibida a reprodução total ou parcial do trabalho sem autorização da universidade, da autora e do orientador.

\section{Elisângela Aparecida Alves}

Graduou-se em Comunicação Social com habilitação em Relações Públicas na PUC-PR. Cursou Marketing e Gestão Empresarial na UFSC. Pós-graduada em Língua Portuguesa e Literatura Infantil também pela PUC-PR, é pesquisadora associada da Cátedra UNESCO de Leitura PUC-Rio e professora convidada do curso de Pós-Graduação A Produção do Livro - Do Autor ao Leitor (PUC-Rio). Atua profissionalmente há quinze anos no mercado editorial.

Ficha Catalográfica

Alves, Elisângela Aparecida

Convergência digital e o futuro do livro / Elisângela Alves ; orientadora: Eliana Yunes. - 2010.

$220 \mathrm{f}$ : il. (color.) ; $30 \mathrm{~cm}$

Dissertação (mestrado)-Pontifícia Universidade Católica do Rio de Janeiro, Departamento de Letras, 2010.

Inclui bibliografia

1. Letras - Teses. 2. Livro. 3. Leitura. 4. Novas mídias. 5. Edição 2.0. 6. E-book. I. Yunes, Eliane. II. Pontifícia Universidade Católica do Rio de Janeiro. Departamento de Letras. III. Título.

CDD: 800 


\section{Agradecimentos}

Aos meus pais e meus irmãos pelo carinho e apoio.

À Prof ${ }^{\circ}$ Dra Eliana Yunes pela paciência na orientação e incentivo que tornaram possível a conclusão desta dissertação.

A equipe de pesquisadores da Cátedra UNESCO de Leitura PUC-Rio pelo convívio, pelo apoio, pela compreensão e pela amizade.

A Capes e aos professores da Universidad Nacional de Rosario pelas valiosas referências e pelo carinho com que me receberam.

Aos amigos, pelo incentivo e apoio constantes. 


\title{
Resumo
}

\begin{abstract}
Alves, Elisangela Aparecida; Garcia, Eliana Lúcia Madureira Yunes. Convergência digital e o futuro do livro. Rio de Janeiro, 2010. 220p. Dissertação de Mestrado - Departamento de Letras, Pontifícia Universidade Católica do Rio de Janeiro.
\end{abstract}

A convergência entre as novas tecnologias e a literatura se escreve no processo de evolução do conhecimento humano ao longo da história. O livro é o meio mais antigo para armazenar, recuperar e transmitir conhecimentos, a edição tradicional se baseia em uma cadeia que une: autores, editores, distribuidores, livreiros, bibliotecarios e leitores. Essa encadeação quase ancestral está sofrendo uma modificação radical com os novos meios de produção e geração de conteúdo digital. Suas ferramentas geram novas formas de criar, difundir e consumir conteúdos, simultanea e conjuntamente, estimulando um novo tipo de edição, a edição 2.0. Um estudo sobre o futuro do livro aponta necessariamente para um estudo da virtualidade e suas implicações, de modo que o livro possa ser repensado diante do processo de transformação, tecnologico e cultural gerado pelos fenômenos (redes sociais, blogs, wikis etc) dessa convergência. O objetivo dessa pesquisa não é estudar a literatura segundo os estudos midiáticos, mas nos apropriarmos dos termos e conceitos que constroem esse objeto e propor uma análise das interfaces entre os meios, avaliando em medida se dá essa remediação - tal como propôs Marshall MacLuhan e o fez Friedrich Kittler -, aportando um marco mais amplo para resolver as relações entre a arte, a estética e a tecnologia, buscando neste quadro teórico algumas contribuições para essas questões.

\section{Palavras-chave}

Livro; leitura; escritura; hipermídia; e-book; edição 2.0. 


\section{Abstract}

Alves, Elisangela Aparecida; Garcia, Eliana Lúcia Madureira Yunes (Advisor). The digital convergence and the future of the book. Rio de Janeiro, 2010. 220p. MSc. Dissertation - Departamento de Letras, Pontifícia Universidade Católica do Rio de Janeiro.

The convergence between the new technologies and literature inscribes itself in the human knowledge evolution process throughout history. The book is the oldest support for storing, recovering and transmiting knowledge; the traditional edition is based on a chain that joins authors, publishers, deliverers, booksellers, librarians and readers. This almost ancestral bookbinding is coping with a radical change using new means of production and generation of digital content. Its tools generate new forms to create, to spread out and to consume contents, simultaneously and jointly, stimulating a new type of edition, the edition 2.0. A study on the future of the book necessarily points out to a study of virtuality and its implications, in way that the book can be rethink ahead of the transformation process, technological and cultural generated by the phenomena (social nets, blogs, wikis etc) of this convergence. The objective of this research is not to study literature according to media studies, but to appropriate of the terms and concepts that construct this object and to consider an interface analysis between the media, evaluating in measure if of this remediation - as proposed by Marshall McLuhan and made by Friedrich Kittler -, settling a broader landmark to decide the relations between art, aesthetic and technology, aiming to contribute for these issues in this theoretical frame.

\section{Keywords}

Book; literacy; reading; writing; hypermedia; e-book; edition 2.0 


\section{Sumário}

$\begin{array}{ll}\text { INTRODUÇÃO } & 09\end{array}$

1. O LIVRO E A REVOLUÇÃO DAS MÍDIAS 14

1.1 O mapa de uma revolução: Inovações e Concorrências 16

1.2 Do receptor ao usuário 20

1.2.1 Primeiro paradigma (1985-1992): Os usuários só lêem 20

1.2.2 Segundo paradigma (1993-1996): Os usuários lêem e 22

1.2.3 Terceiro paradigma (1997-2000): A interatividade 24

1.2.4 Quarto paradigma (2001-2004) 25

1.2.5 Quinto paradigma (2004-hoje): O usuário e a Web 27

$1.3 \quad$ Novas teorias para os novos meios? 29

1.3.1 O hipertexto 34

1.3.2 Interatividade 38

1.3.3 Multimidialidade: Mediação e Remediação tecnológica 41

1.3.4 Hipermidialidade, Cibercultura e Ciberespaço: discutindo Conceitos

1.4 Do usuário ativo ao participativo 50

1.5 O ambiente comunicacional contemporâneo 53

1.5.1 A cibersocialidade contemporânea 58

2. DA CULTURA IMPRESSA À HIPERMÍDIA 70

$\begin{array}{lll}2.1 & \text { Do autor ao leitor } & 71\end{array}$

2.2 Do navegador ao texto 73

2.3 Da materialidade da leitura $\quad 81$

2.4 Da textualidade digital 88

2.5 Da leitura à narratividade digital 95

2.6 Da reticularidades à ciberliteratura 104

$\begin{array}{lll}2.7 & \text { Weblogs na Educação } & 112\end{array}$

$\begin{array}{ll}\text { 2.7.1 Weblogs coletivos } & 112\end{array}$

2.7.2 Blogueiros e lurkers: a leitura na web 114

2.7.3 Individualismo, tecnologia e comunicação 116

$\begin{array}{ll}\text { 2.7.4 O Skywriting e o surgimento das } & \\ \text { ferramentas colaborativas } & 117\end{array}$

3. ESCRITO EM BITS: O FUTURO DIGITAL DO LIVRO 119

3.1 O Livro e os Avanços Tecnológicos 125

3.1.1 Livros virtuais ou e-books? 132

3.2 As profecias sobre o fim do livro 142

4. A INDÚSTRIA EDITORIAL: DA GALÁXIA DE

4.1 Revolução Gutenberguiana: autores, copistas, impressores e livreiros 146

4.1.2 A invenção da difusão de massa: produção e mercado 151 
4.2 O mercado editoral brasileiro: do codex a tela 157

4.2.2 Indústria editorial brasileira e o mercado consumidor 166

4.3 Evolução da indústria editorial e seu potencial de Reconfiguração

4.3.2 A Editora: transformações guiadas pelo consumidor $\quad 174$

4.3.3 A Livraria: transformações guiadas pelo mercado 183

4.3.3.1 Amazon: o novo mundo digital 193

5. CONCLUSÃO 205

6. REFERÊNCIAS 212 